Proc. Indian Acad. Sci. (Earth Planet. Sci.), Vol. 90, Number 1, March 1981, pp. 63-74. (C) Printed in India.

\title{
Seismic ray direction anomalies and relative residuals of earthquakes recorded at Gauribidanur array
}

\author{
AVADH RAM, LALAJI YADAV and O P SINGH \\ Dopartment of Goophysics, Banaras Findu University, Varanasi 221005 , India \\ MS receivod 22 April 1980; rovised 9 Pobruary 1981
}

\begin{abstract}
Slowness and azimuthal anomalies provide valuable information about lateral inhomogencities within the crust and mantle of the earth. Over 300 earthquakes (distance range $14^{\circ}-36^{\circ}$ and azimuth $0^{\circ}-360^{\circ}$ ) recorded at Gauribidanur seismic array (GBA) in southern India, wero analysed using adaptive processing tochniques. Slowness anomalies upto $1 \cdot 3 \mathrm{sec} / \mathrm{deg}$ and azimuthal anomalies upto $8^{\circ}$ have been observed in the present analysis. Slowness anomaly patterns for Java trench, Mid-Indian oceanic ridge carthquakes are more consistent as compared to the events originating in the Himalayan and Hindukush rogions. A significant feature of the azimuthal anomaly pattern was the distinct absence of any positive anomalies from earthquakes occurring in mid-oceanic ridge. These anomalies have also been analysed as a function of epicentral distance and are mainly attributed to the transition zones occurring between $400-700 \mathrm{~km}$ depth ranges in the Indian upper mantle regions. Relative residuals between the stations of GBA have very little dependence on azimuth and distance. An anomalous structure beneath tho array in the direction of the Java trench region (azimuth 116-126 ) has been postulatod on the basis of large systematic slowness vectors observed.
\end{abstract}

Keywords. Seismic array; slownoss and azimuthal anomalios; relative residuals; earthquakes.

\section{Introduction}

Seismic ray direction anomalies provide important information regarding the lateral inhomogeneities present in the earth. Several studies have been carried out in the p3st to observe the deviations of spherical symmetric earth (Davies and Sheppard 1972; Kanasewich et al 1973; Wright et al 1974; Noponen 1974; Kulhanek and Brown 1974 ; Powell 1975). The sources of anomalous slowness and azimuth observations have been attributed in the three critical areas:

(i) strong lateral variations at the source region, (ii) crust and upper mantle structure beneath the recording sites and (iii) the turning point of the seismic ray tubes. The most sensitive portion of the ray path to the lateral variations in the structures occurs in the regions where the rays bottom and in the region directly bəneath the recording stations. Large systematic part of seismic ray direction 
anomalies is used to infer the crust and upper mantle structure beneath the recording sites and remaining fine details are assumed to be diagnostic of structure near the deepest point of the ray path

Anomalous residuals have been used to study inhomogeneities in the physical properties of the earth near the source regions, along the propagation paths of the seismic rays and beneath the recording stations. A number of investigations on $P$-wave residuals have been carried out during the past fifteen years (Cleary and Hales 1966; Herrin and Taggart 1968; Nuttli and Bolt 1969; Julian and Sengupta 1973; Iyer and Healy 1972; Iyer 1975). Davies and McKenzie (1969) examined the residuals to delineate the nature of the plates such as angle of dip and strike. The source and path effects can be isolated from the effect of any anomalous structure present in the immediate vicinity of array by choosing a reference station. The selection of reference station is important in that it should be at a geologically uniform site, with no local anomalies involved. In case of GBA, the cross-over point (CP) of the two arms is chosen as a reference station to find out the relative residuals between the stations of the array. The variation of the relative residuals with distance or azimuth across the array should reflect differences in the structures in the neighbourhood of the recording stations e.g., thickening or thinning of the underlying crust, a dipping Moho or heterogeneities present in the uppermost mantle directly below the stations.

In the present paper, over three hundred earthquakes (distance $14^{\circ}-36^{\circ}$ and azimuth $0^{\circ}-360^{\circ}$ ) recorded at Gauribidanur seismic array in southern India have been considered. The earthquake data was classified into four epicentral zones, viz., 1. Himalayan region (azimuth $\left.0^{\circ}-90^{\circ}\right)$, 2. Java trench region $\left(90^{\circ}-180^{\circ}\right.$ ), 3. Mid-Indian oceanic ridge $\left(180^{\circ}-280^{\circ}\right)$ and 4 . Hindukush region $\left(280^{\circ}-360^{\circ}\right)$. Epicentral locations of all these earthquakes are shown in figure 1. Short period $P$-wave rezording up to $36 \mathrm{sec}$ were processed using adaptive cross-correlation filtering technique. Slowness and azimuthal anomalies for first arrivals were obtained and these have been analysed in detail. Relative time residuals have been determined for these events. They have been examined for different regions separately. Large systematic ray direction anomalies from Java trench events (azimuth $116^{\circ}-126^{\circ}$ ) have been observed. A ray geometry for this region is also illustrated.

\section{Array configuration and data analysis}

Gauribidanur seismic array (GBA), located in Southern India, is a medium aperture array sponsored by UK Atomic Energy Authority (UKAEA) with the cooperation of the Bhabha Atomic Research Centre (BARC), Government of India (Ram and Mereu 1977). Detailed specifications for the UKAEA medium aperture seismic arrays were described in the form of a hand-book by Mowat and Burch (1974) in an Atomic Weapons Research Establishment (AWRE) report.

The measurements of slowness and azimuths of short period $P$-wave arrivals of over 300 earthquakes were made using adaptive processing technique (Mereu and Ram 1975). In this method the apparent velocity, slowness and azimuth are filtered using least square technique (Otsuka 1966). The respective arrival time at each sensor were determined by cross-correlations of the beam with each channel. 


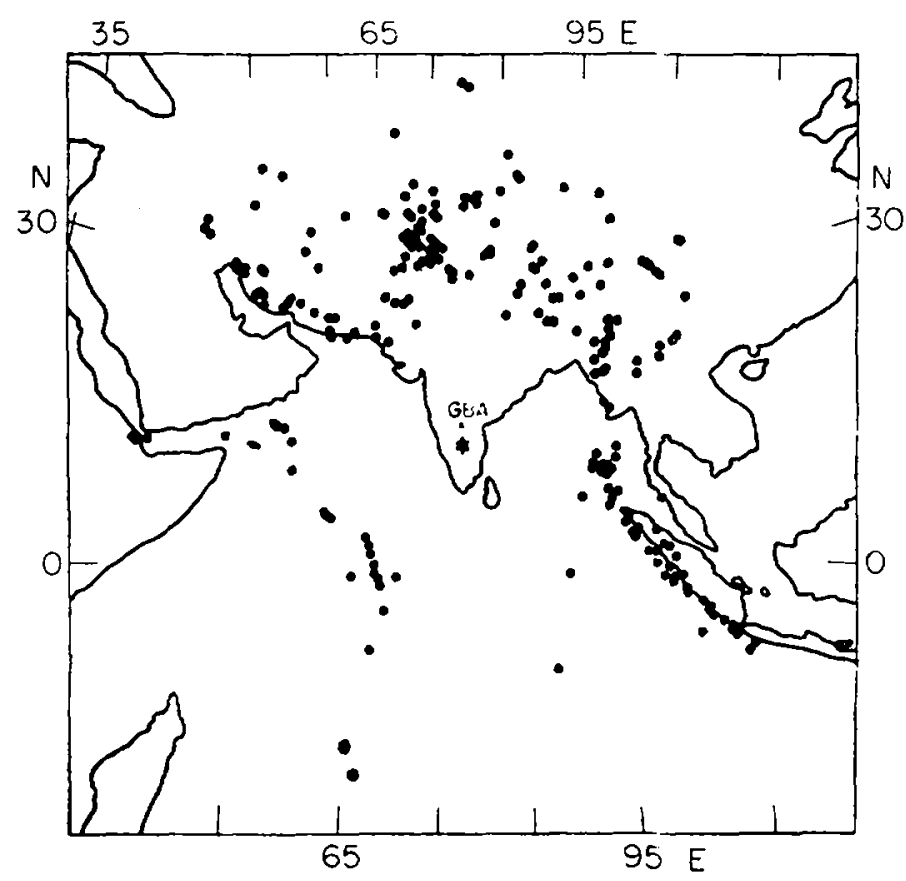

Figure 1. Epicentral map for earthquakes used in the present analysis (Distance range $14^{\circ}-36^{\circ}$; Azimuth range $0^{\circ}-360^{\circ}$ ).

All events were band pass $(0 \cdot 4-3 \cdot 0 \mathrm{~Hz})$ filtered before processing. The meaningful measurements of slowness and apparent azimuths over the onsets as well as later arrivals were selected and weighted mean of these quantities were taken. No results of events were included if the mean correlation coefficient fell below 0.94. The precision of slowness measurements for good signal was better than $0.1 \mathrm{sec} / \mathrm{deg}$. Local structure correction was not applied in the slowness data mainly because this information was not known. Corbishley (1970) showed that GBA is situated essentially on a uniform horizontal structure with the site corrections being almost negligible. The other studies by Ram and Mereu (1977) and Berteussen et al (1977) showed that the structure, in general, beneath the array is relatively homogeneous.

\section{Slowness and azimuthal anomalies as a function of epicentral distance}

The apparent slowness and azimuth values were calculated for first arrivals of each earthquake and were compared to theoretical values as expected from a standard JB earth model. Slowness anomalies upto $1.3 \mathrm{sec} / \mathrm{deg}$ and azimuthal anomalies upto $8^{\circ}$ were observed in most cases of this study. These anomalies have been plotted as a function of corrected epicentral distance for different azimuthal ranges, i.e., Himalayan region $\left(0^{\circ}-90^{\circ}\right)$, Java trench region $\left(90^{\circ}-180^{\circ}\right)$, Mid-Indian oceanic ridge $\left(180^{\circ}-280^{\circ}\right)$ and Hindukush region $\left(280^{\circ}-360^{\circ}\right)$. In all these cases positive as well as negative anomalies are observed. 
The complete set of observations from Himalayan region are shown in figure $2 a$. This figure reveals that slowness anomalies are negative before $18^{\circ}$ and then show positive bias upto $21^{\circ}$. Between $21^{\circ}$ and $24^{\circ}$ distance range, it shows positive as well as negative bias after which it has negative bias upto $31^{\circ}$. Azimuthal anomalies do not show any consistent pattern. However, these are mostly negative beyond $23^{\circ}$ epicentral distance implying that rays have followed more northernly path. Abrupt change of negative to positive anomaly shows clear evidence of $18^{\circ}$ discontinuity which is very sharp. For this region, no sharp discontinuity near $23^{\circ}$ (about $650 \mathrm{~km}$ depth range) was observed by Ram and Mereu (1977) which is also suggested by this data.

A complete set of seismic ray direction anomalies from Java trench region is shown in figure $2 b$. It is clear from this figure that around $17^{\circ}$ these anomalies show positive as well as negative bias. After $23^{\circ}$, all the anomalies show negative bias. No systematic pattern for azimuthal anomalies is observed for this region for all distance ranges. Anomalies from mid-Indian oceanic ridge are presented in figure $2 \mathrm{c}$, which reveal negative bias near $18^{\circ}$ for slowness as well as azimuthal anomalies. It implies that rays have deflected towards south while reaching at GBA. It is not possible to demarcate the nature of the velocity variation in the transition zone near $650 \mathrm{~km}$ depth, for this region, because of scanty data in this distance range.

Observations from Hindukush region (figure $2 d$ ) show the positive as well as negative bias before $18^{\circ}$ after which negative bias is not observed in slowness

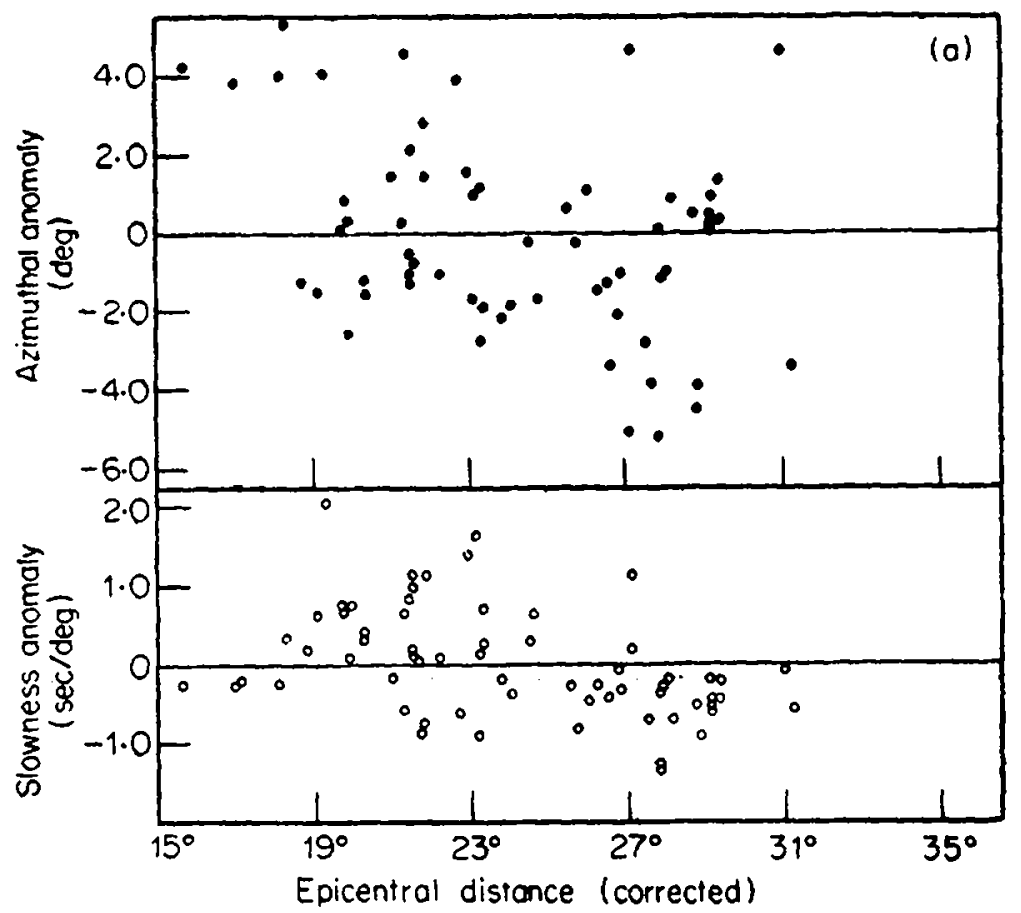

Figure 2. Variation of slowness and azimuthal anomalies with epicentral distance for (a) Himalayan Rogion (wimuth $0^{\circ}-90^{\circ}$ ): 


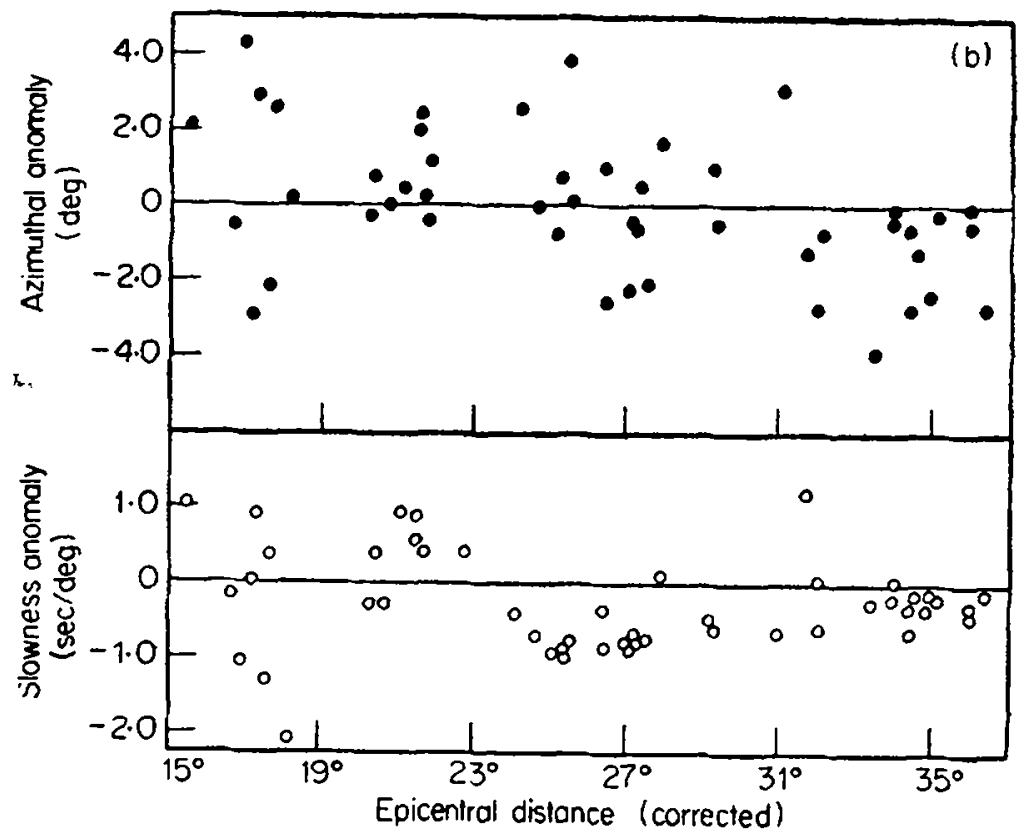

Figure 2b. Java trench region (azimuth $90^{\circ}-180^{\circ}$ ).

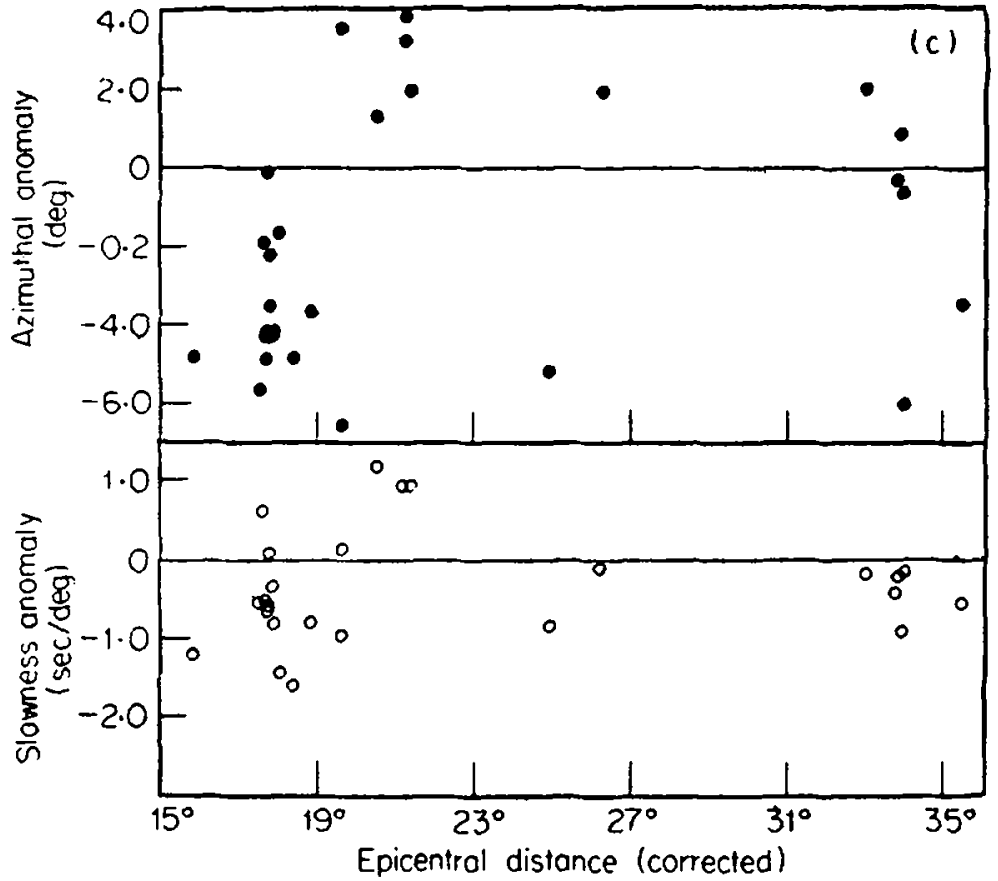

Figure 2c. Mid-Indian octanic rides (azimuth $180^{\circ}-280^{\circ}$ ), 


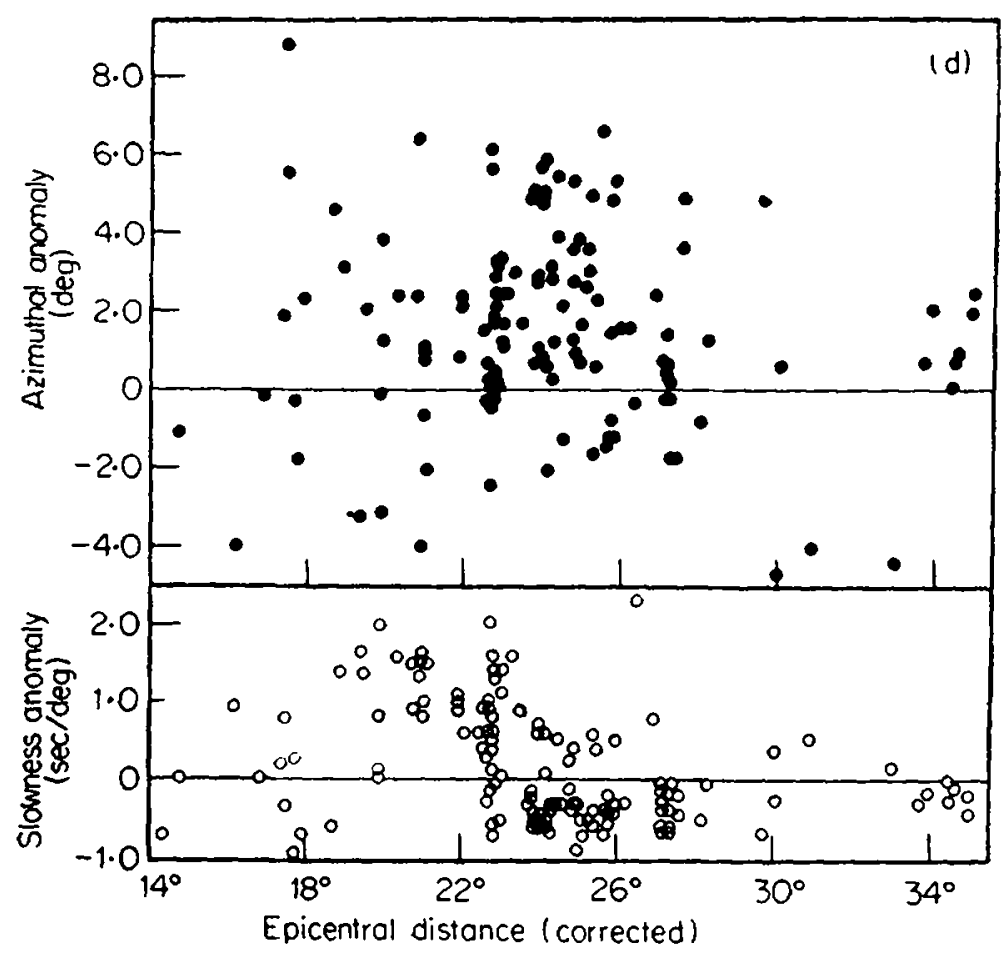

Figure 2d. Hindukush region $\left(280^{\circ}-360^{\circ}\right)$.

anomaly upto $22^{\circ}$ epicentral distance bosides sufficiont observations in this distance range. In the present case, the mislocations are characterised by higher slowness deviations (for positive bias) for epicentral distances less than $23^{\circ}$ and lower slowness deviations for greater epicentral distances. However, azimuthal anomalies show positive bias in most of the obiervations which implies that most of the ray tubes have been deflected northward during their transmission path while reaching at GBA. The slowness anomaly pattern shows an abrupt change just before $23^{\circ}$ (corresponding depth of about $650 \mathrm{~km}$ ) suggesting that the velocity gradients are much more pronounced around this depth as compared to the shallower depth. However, its value is increased further as one considers the sampled zone below $625 \mathrm{~km}$ dopth. This suggests the presence of transition zone around $23^{\circ}$.

\section{Rolative time residuals}

Averaged-relative residuals for the first arrivals of all the GBA events were analysed to find out any consistent patterns. The relative residuals at each station were computed from the formula :

$$
\varepsilon_{t}=T_{0}-T_{1}-x_{i} P-y_{t} Q,
$$

where $\varepsilon_{\text {o }}$ is time residual at station $i$ between the least squares fit to the wavefront and the measured arrival time (Kelly 1964; Otsuka 1966). 
$T_{0}$ be the arrival time of wavefront at origin [origin is chosen at point of intersection of the two arms of an array or cross over point (CP)].

$x_{i}$ and $y_{6}$ be the coordinates of the seismometers $S_{i}$ in an array configuration. $T$, be arrival time of wavefront at $S_{3}$.

$$
P=\sin \phi / V \text { and } Q=\cos \phi / V .
$$

$V$ and $\phi$ are the apparent velocity and azimuth of a seismic wave crossing the array.

These residuals between the stations of GBA are separately presented for each of the four zones classified in the preceding paragraphs (figure 3). Averagedrelative time residuals for four regions vary between $\pm 0.025 \mathrm{sec}$ for most of the observations. No regular pattern of relative time residuals in a particular direction was obtained that can be interpreted as thickening or thinning of the crust beneath the recording sites. However, it can be seen from this diagram that the patterns are more or less similar for all regions except Java trench region. This may be interpreted as due to very near subsurface irregularities beneath recording sites. The dependence of relative residuals on azimuth and distance was also examined for each of the regions and it was found that these residuals have very little dependence on azimuth and distance, thus further indicating that main sources of these residual variations observed are probably localized beneath the array. A typical example of variations of relative residuals with distance for the events from Java trench region for the stations $B_{3}$ and $B_{6}$ is illustrated in figure 4 . Relative residuals at these stations vary up to $0.05 \mathrm{sec}$ with almost all the values showing negative bias for all the distances. Figure 5 shows another example of averagedrelative residuals with azimuths for the events from Himalayan region for the stations $\boldsymbol{R}_{\mathbf{G}}$ and $\boldsymbol{R}_{\mathbf{f}}$. It shows that most of the observations have negative bias independent of azimuth for station $\boldsymbol{R}_{6}$ while it does not hold good fosr tation $\boldsymbol{R}_{\mathbf{b}}$.

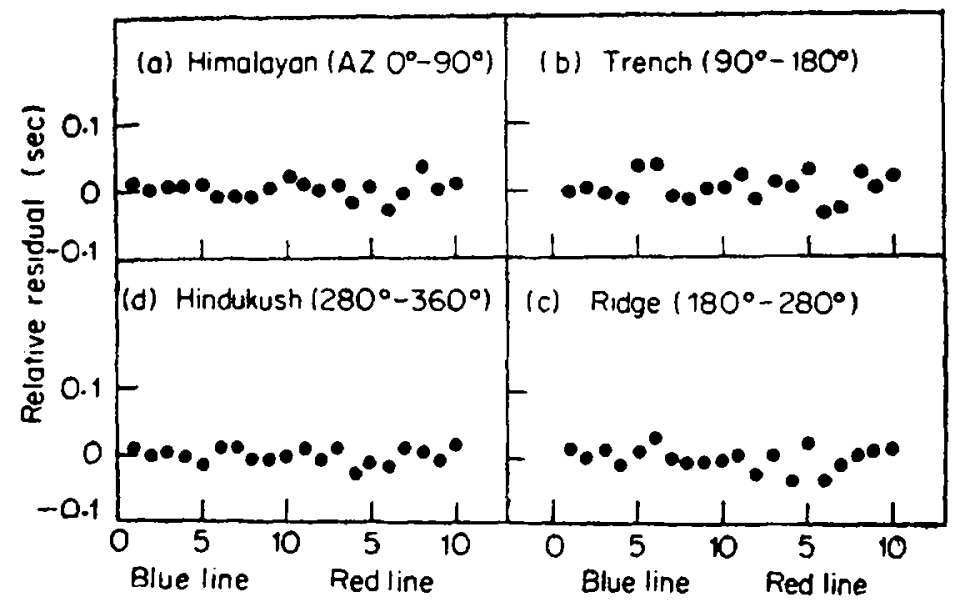

Figure 3. Averaged relative residuals for first arrivals between the stations of GBA frcm (a) Himalayen tegicn (Az $0^{\circ}-90^{\circ}$ ), (b) Java Treach Region (Az $90^{\circ}-180^{\circ}$ ), (c) Mid-indian cceanio ridge (Az $180^{\circ}-280^{\circ}$ ), (d) Hindukush region (Az 80 $-360^{\circ}$ ). 


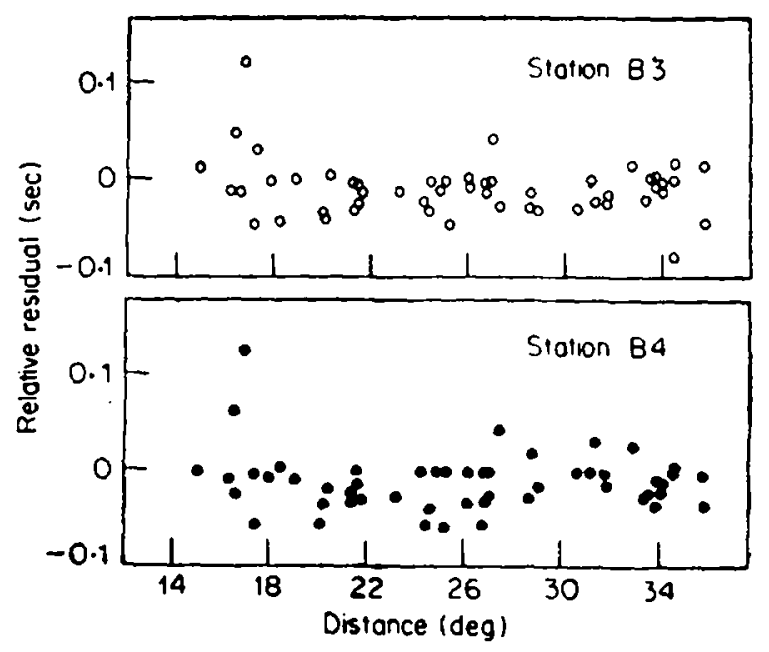

Figure 4. Averaged rolativo residuals with distance at the stations $B_{2}$ and $B_{4}$ of the GBA (Java Trench oarthquakes).

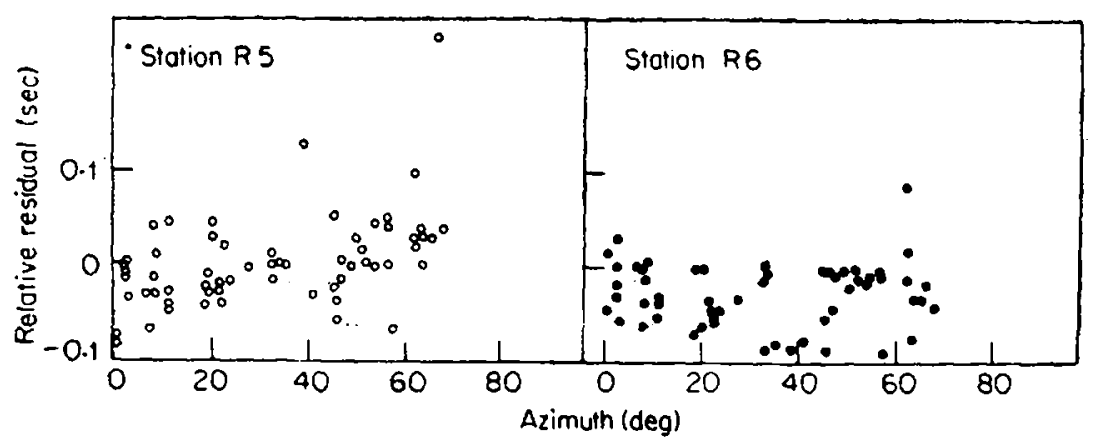

Figure 5: Averaged relative residuals with azimuth at the stations $R_{b}$ and $R_{6}$ of the GBA (Himalayan region events).

\section{Discussion and comclusions}

Seismic ray direction anomalies can be attributed to irregularities beneath the array, structure near the deepest point of the ray path, or marked lateral variations in the source region. To look for the evidence for anomalies in ray direction produced by structure at the region where rays have got their maximum penetration, one must have to eliminate ambiguities introduced by structures other than this region. Large systematic anomalies in ray direction may be probably due to crust upper mantle structure beneath the array and this has been used as an efficient tool for delineating the same by various workers in the past. Niazi (1966) considered the effect of dipping $M$-discontinuity or a simple plane dipping interface to account for the slowness and azimuthal anomalies. The effect of such an interface will introduce approximatoly sinusoidal variations in the azimuth and slowness anomalies as a function of great circle azimuth. Ram and Mereu 


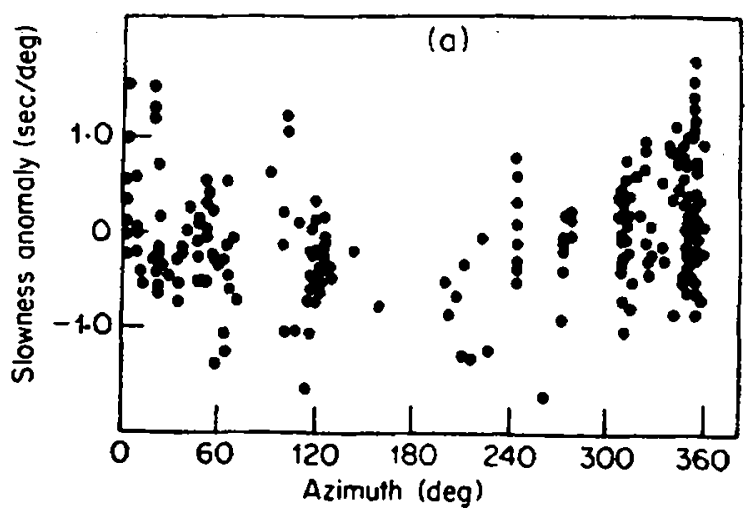

Figure 6a. Slowness anomalies as a furction of azimuth for first arrivals for all events.

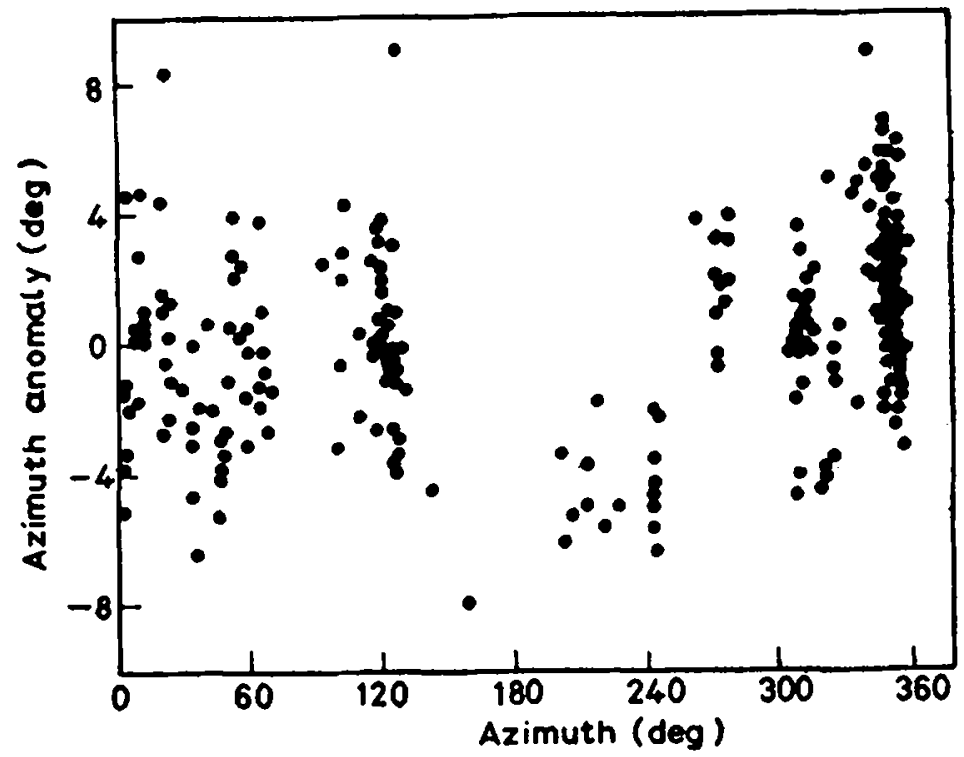

Figure 6h. Azimuth anomalies as a function of azimuth for all events (after Ram and Mereu 1977).

(1977) have not found such sinusoidal variations of anomalies as a function of great circle azimuth in the case of GBA as shown in figures $6 \mathrm{a}$ and $6 \mathrm{~b}$. Berteussen et al (1977) have found that the residual anomalies at GBA were explained in a satisfactory manner if a dipping plane coincident with Moho introduced, with a dip of $6^{\circ}$ and striking $N 13^{\circ} \mathrm{E}$ as compared to a dip of about $4^{\circ}$ and striking $\mathrm{N} 50^{\circ} \mathrm{E}$ as postulated by Arora et al (1970). In the present study, it was found that relative residuals have very little dependence on azimuth and distance, thus indicating that the main source of these residual variations observed are probably localized beneath the array Niazi (1966) has concluded that for epicentral distances less than $30^{\circ}$, simple plane dipping beneath the array could not produce more than $10 \%$ effect on slowness even in extreme cases However, our results indicate both positive as well as negative slowness anomalies for specific distance ranges for different azimuths $\left(0-360^{\circ}\right)$. Whatever be the effect of crust 
and upper mantle structure beneath the array, it will not affect the contrast between positive and negative slowness anomalies at specific distance especially for a particular azimuthal range.

Brown (1973) mentioned that lateral heterogeneity in $P$-velocity will affect azimuth more and slowness less when the ray segment is closer to horizontal, which implies that slowness reflects rather deeper causes than azimuth. However, Noponen (1974) considered that horizontal velocity gradients closer to the array than to the sources seemed to be probable causes for the slowness deviations. However, the behaviour of a ray is most strongly influenced by the gradient of the velocity structure tangent to the ray path. This gradient is largest near the turning point of the ray, except in cases of strong lateral variations near the source or receiver. Davies and Sheppard (1972), using data from LASA, also concluded that the main source of the slowness anomalies observed are in the mantle. These conclusions suggest that slowness anomaly reflects almost negligible cause from source region. There may be additional effect of source region and crust and upper mantle structure beneath the array on the ray direction anomalies.

A comparison of cantinental and oceanic upper mantle structures, based on the detailed analysis of travel time branches and slowness data, has revealed that significant lateral variations are present in the Indian upper mantle regions. The maximum variation in the depths of the twa discontinuities was $\pm 15 \mathrm{~km}$. The maximum uncertainty in the $P$-wave velocity distribution at a particular depth other than transition zones was approximately $\pm 0.05 \mathrm{~km} / \mathrm{sec}$ whereas within the transition zones $\pm 0.15 \mathrm{~km} / \mathrm{sec}$. A detailed discussion on velocity structure can be found eisewhere (Ram and Mereu 1977). A checking was also made after computing the slowness and azimuthal anomalies using these velocity models which agreed well with the observed anomalies. For the events from Himalayan region, slowness anomaly pattern for transition zone around $23^{\circ}$ (corresponding depth of about $650 \mathrm{~km}$ ) is replaced by a relatively small velocity gradient, and velocity increases steadily from $21^{\circ}$ (depth of about $425 \mathrm{~km}$ ). The nature of change in velocity near $18^{\circ}$ is similar for the continental regions. However, this jump in velocities at this distance range is broader in oceanic regions. This may have been the result of the introduction of the low velocity zones in the upper mantle of these regions. The depth of $23^{\circ}$ discontinuity for the events from Java trench region varios significantly, however, it was not possible to demarcate such seismic behaviour for the events from mid-Indian oceanic ridge due to paucity of data around this distance range. Although both regions are the oceanic, the trenches and mid-oceanic ridges are results of two different tectonic processes. The former originates from the descending convection currents whereas the latter is from rising currents prevailing in the upper mantle of the earth.

Arora (1971) postulated a two-layered hypothetical crustal model in the vicinity of GBA with top granitic layer $16 \mathrm{~km}$ thick and the Moho boing at $35 \mathrm{~km}$ depth. He also observed that $P$ and $S$ wave velocities were somewhat lower and higher respectively as compared to the global average. In another study, Arora et al (1970) used a series of local earthquakes recorded at GBA to delinoate the crustal structure of southern India. They observed that the Moho-refracted phase from approximately the $\mathrm{N}$-E direction emerges at smaller angles as compared to other directions. This argument has lod them to believe that it could be due to non- 


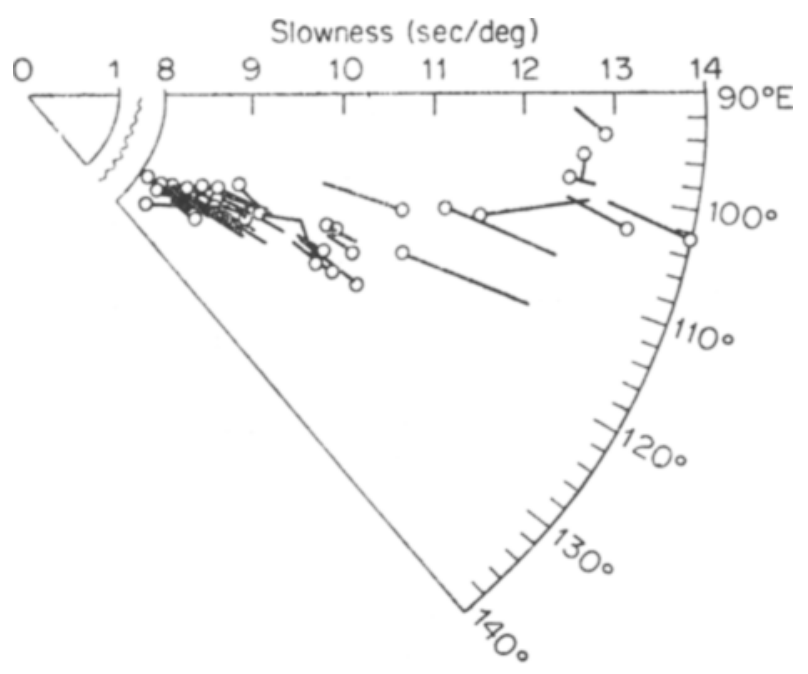

Figure 7. Slowness and azimuth anomalies of first arrivals of Java trench earthquakes recorded at Gauribidanur array as represented in the form of an array diagram. Each vector line segment represents an observation which starts (tail) at the slowness value determined from JB earth model and the great circle aximuth as obtained from NOAA listings and ends (head) at the observed slowness and azimuth values.
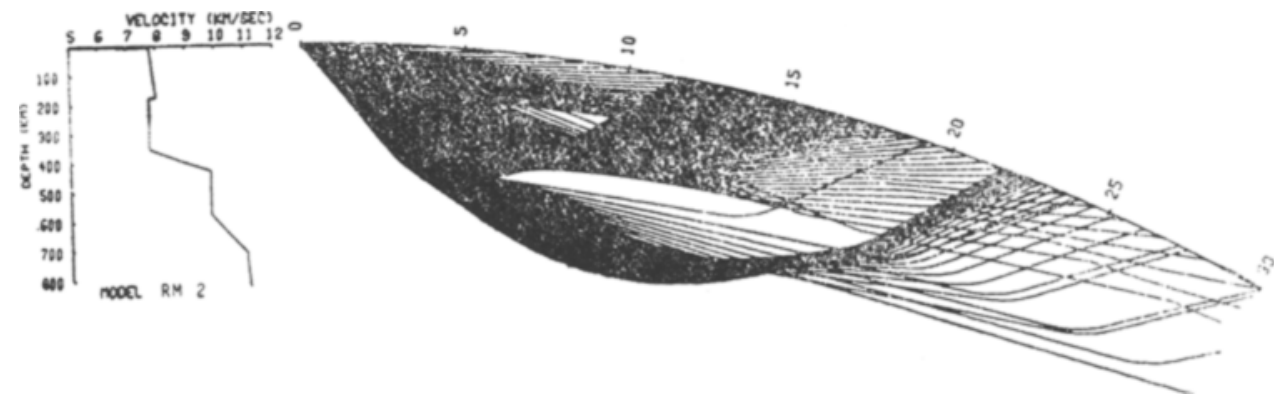

Figure 8. Velocity model and the ray geometry as obtained from earthquakes occurring in the Java trench region.

uniform intermediate layers or a dipping Moho (about $4^{\circ}$ ) in the direction of GBA. In the present study, averaged-relative time residuals obtained for all four regions are insignificant as the point of thickening or thinning of the crust is concerned and their causes may be considered very localized beneath the recording sites.

Several studies in the past have revealed that GBA is situated on a homogeneous structure (Corbishley 1970; Ram and Mereu 1977; Berteussen et al 1977). However, we have observed large systematic slowness vectors for the events occurring in the particular azimuthal range, $116^{\circ}-126^{\circ}$ (Java trench region) as shown in figure 7. This indicates that some anomalous structure might be present at least 
from this direction. Contribution of the sources to these systomatic mislocation does not seem to offer a plausible explanation because sources are at varying focal depths with different epicentral distances. A ray geometry for the structure between source and receiver for this region is shown in figure 8. This ray tracing for the given velocity model is based on geometrical ray theory. It provides quantitative estimates on the velocity perturbations within the earth. Emergence of various seismic rays for the model can be seen from this ray geometry. It is interesting to point out that anomalously low slowness observations were obtained for this direction while analysing earthquakes in the distance range $40^{\circ}-70^{\circ}$ (Ram 1976). We are computing the structure for this case in the light of these investigations using Niazi (1966) equations. The corresponding structural corrections would be published elsewhere.

\section{Acknowledgements}

Part of the processing of the earthquake data was carried out at the University of Western Ontario, London, Canada. We are grateful to Prof. C L Singh, Head of the Department, for facilities. Thanks are also due to Mr M C S Kulbhushan for his prompt efforts in making the diagrams. Financial assistance to two of us (LY and OPS) by CSIR, New Delhi, is thankfully acknowledged. We also record our appreciation for the comments made by two referees.

\section{References}

Arora S K, Varghese T G and Krishnan C A 1970 Nature (London) 225261

Arora S K 1971 Bull. Seism. Soc. Am. 61671

Berteussen K A, Husobye E S, Mereu R F and Ram A 1977 Earth Planet. Sci. Lett. 37326

Brown R J 1973 Pure Appl. Geophys. 1091623

Cleary M A and Hales A L 1966 Bull. Seism. Soc. Am. 56467

Corbishley D J 1970 Geophos. J. R. Astr. Soc. 21415

Davios D and McKenzie D P 1969 Geophys. J. R. Astr. Soc. 1851

Davies D and Sheppard R M 1972 Nature (London) 239318

Herrin E and Taggart J 1968 Bull. Selsm. Soc. Am. 581325

Iyer H M 1975 Nature (London) 253425

Iyer H M and Healy J H 1972 J. Geophys. Res. 771503

Julian B R and Sengupta M K 1973 Nature (London) 242443

Kanasewich E R, Hemmings C D and Alpaslan T 1973 Geophysics 38327

Kelly E J 1964 MIT Group Report 44

Kulhanek O and Brown R J 1974 Pure Appl. Geophys. 112597

Mereu R F and Ram A 1975 in Explotiation of seismograph networks ed. K G Beauchamp (NATO Adv. Study Inst. Series) p. 327

Mowat W M H and Burch R F 1974 Hand-book for the stations which provides seismograms to the Blacknest Seismological Centre, UK, AWRE report no. 44/47/29, January

Niazi M 1966 Bull. Seism. Soc. Am. 56491

Nuttli O W and Bolt B A 1969 J. Geophys. Res. 746594

Nopunen I 1974 Bull. Setsm. Soc. Am. 641931

Otsuka M 1966 Bull. Seism. Soc. Am. 56223

Powell C 1975 Nature (London) 25440

Ram A 1976 The identification and interpretation of upper mantie travel time branches from slowness measuremonts made on data recorded at the Gauribidanur (India) and Yellow knife (Canada) seismic arrays, Ph.D. Thesis (University of Western Ontario, London, Canada).

Ram A and Moreu R F 1977 Geophys. J. R. Astr. Soc. 4987

Wright C, Cleary J R and Muirhead K J 1974 Geophys. J. R. Astr. Soc. 36295 